\title{
The Study of English Translations of Chinese Classics in China (1997-2016): Recent Development and Future Prospects
}

\author{
Zhi LI \\ College of International Studies, Southwest University, Chongqing, China
}

\begin{abstract}
Since the 1990s, the study of translated ancient Chinese Classics has been a heated topic for discussion in China, and views have emerged like mushroom after spring rain. Almost all the studies have been made from the cultural, functional and deconstructionalist perspectives, which concentrate primarily on translating strategies and principles. However, the following problems that arise in the studies remain to be solved: reduplicate studies of the same translated text or book (from the same perspective, such as cultural), disintegration of theories and practice, abstract and impractical theories in the study, unsystematic analysis and comparison of translated texts and personal preference in the choice of translated texts to be researched. Therefore, this paper has provided the following points for readers' consideration: to broaden the object of study by choosing non-literary texts, to attach much importance to the study of social, cultural and esthetical elements of the translated texts, and to describe the translator's process of translation, purpose, and decision such as translating strategies, and to analyze translator's choice of source texts and choice of words by using corpus-based approach, and summarize translator's own research of Chinese Classics to be translated.
\end{abstract}

Keywords: English version of ancient Chinese Classics, study, perspective, suggestions

\section{Introduction}

The last two decades has witnessed substantial progress in the translation of traditional Chinese Classics. Similarly, the increasing number of the translated Chinese Classics has enabled researchers to grant much consideration to such texts themselves, which has become an inseparable part of translation studies in China. In actual fact, some academics embarked on their research of the translated Classics in the 1980s. The Analects, A Dream of Red Mansions, and The Old Drunkard's Arbour became some scholars' first choice. Particularly, they concentrated primarily upon the gains or losses of the translated texts at the lexical and syntactical levels, translator's translating strategies and translating principles, almost based upon some translation theories. Such analysis or appreciation of the translated texts established a foundation for the extensive research of the translated English texts in the 1990s. This paper undertakes to summarize progress in the research of the translated texts of Chinese Classics over the last 20 years, points out their strong points and weak points and provides some possible suggestions to promote the study of the translated texts of Chinese Classics in China.

Zhi LI, associate professor, Ph.D., College of International Studies, Southwest University. Research interest: Aesthetics-oriented translation studies, study of translated modern \& classic Chinese texts. 


\section{The Previous Study of Translated Texts of Chinese Classics in China}

Undoubtedly, Chinese Classics, as an essential part of Chinese culture, have been valued as a treasure both to China and to the rest of the whole world. The translation of the Chinese Classics has become an unswerving responsibility to translators in China and abroad. Likewise, the study of their translated texts should justifiably be their important research program in order to make their investigations shared by their foreign peers. In particular, the study of English texts has become the top program. To some degree, such a study will be exceedingly helpful to improve the translation of Chinese Classics in return.

The first and most remarkable trend in the study of translated Chinese Classics in China is the rapid growth of the field, whether we speak in terms of the number of scholars specializing in them, the number of published works devoted to them, or the number of conferences, seminars, workshops closely related to them. A few examples can bear this out. According to CNKI online under the general heading of the English versions of Chinese Classics with a span of 20 years (1997-2016), at least 3,500 items are listed, of which there are more than 1,000 articles, 230 dissertations and theses, and 9 summaries of conferences. In addition, there have been about 15 books ever published.

Together with such a quantitative increase of the field, there has been a growing tendency to recognize the study of the translations (particularly English Translations) of Chinese Classics as a discipline in itself rather than a part of Cultural Study only. To avoid any misunderstanding, we have to make it clear that those scholars who prefer to consider themselves as literary critics or literary historians specializing in Chinese Classics rather than as translation theorists do not belittle the importance of other disciplines; on the contrary, they believe that historical and cultural knowledge can be a prerequisite for the study of English versions of Chinese Classics themselves. Nevertheless, they conceive their central concern to be the study of intrinsic qualities of the English versions of Chinese Classics as an autonomous cultural phenomenon, not the study of translated texts as social documents or linguistic data. Anyway, such scholars are free to employ translated texts as sources of information from the different perspectives, and their research results do not only constitute literary studies but an inseparable part of translation studies.

Actually, early research of the translated texts (e.g., English versions) of Chinese Classics focused heavily upon topics such as the form and spirit of the translated texts, accuracy and faithfulness, adequate representation of the meaning and language points, which provide penetrating insight into translation studies. Such investigations, however, were largely characterized by prescriptive study. An Analysis of the Old Drunkard's Arbour translated by A. Giles, for instance, falls under such a category. The study of Books of Songs and The Analects featured micro levels, with the analysis of words, phrases, sentences and texts. More efforts have been made to compare different English versions of one original text. It has presented a full picture of prosperity in the investigation of some translated Chinese Classics over the past two decades. The perspectives are not limited to casual thinking of or reflection on the translations. The researchers have enlarged their research scopes and methods, for instance, the subjectivity of translators, aesthetics-based analysis of the translated texts, and hermeneutics-oriented study, which have paved a new way for the research of the translated Chinese Classics.

Another main trend accompanied by the quantitative growth of the field is the increasing diversity of interests in terms of genres. Before 2000, most researchers' interest in the translated texts of classic works has 
been majorly confined to Classic poetry and literary criticism such as Wen Xin Diao Long or The Literary Mind and the Carving of Dragon, Hong Lou Meng or A Dream of Red Mansions, The Analects of Confucius. The study of some non-literary works like Ben Cao Gang mu and Shui Jing Zhu has almost fallen into oblivion. Fortunately, the introduction of the Western translation theories into China as well as the translation studies in the West with cultural turn has broadened Chinese translation theorists' horizon since the 1990s. A great many researchers have embarked upon the pursuit of meticulous analysis of the translations and the interpretation of some translation thoughts. To be more specific, they have undertaken to analyze the English versions of Chinese Classics at the pragmatic, linguistic and cultural levels. The analysis of the translated texts has been increasingly theoretically diverse. In a sense, the Chinese translation theories have completely blended with the Western theories.

In other words, the casual and impressionistic reflection and commentary study have gradually given way to descriptive translation studies, which have access to the freedom of translation studies in China. Some problems have, however, still arisen in the study of the translated Chinese Classics. For example, too much energy was spent upon some translated texts, and drab analysis was repeated. Mountains of researches of A Dream of Red Mansions were made, in which the study of the dialogues of the main characters has remained nearly untouched so far. The researchers have unanimously employed the cultural perspective in the study of Redology (the study of $A$ Dream of Red Mansions) and Outlaws of the Marshes. The translated texts of Book of Songs, the Art of War have been investigated from the cross-cultural, aesthetic and cognitive linguistic angle. Such researches have more or less played a pioneering role over the past 20 years. Even in the research of translated poems, some scholars have prioritized Tang Poems over the Song Tze. FAN Yue (2006) has pointed out in English Translation on Chinese Ancient Literature and Philosophy that the study English texts of Chinese Classics, based one concept, should be made in a system. JIANG and PENG (2006) have presented their viewpoints that the study of English texts of Chinese Classics is absolutely essential and possible from the cultural perspective, and contextuality theory can provide possibility for synchronic and diachronic research of English texts. On the one hand, researchers can explore the culture-bound factors in the English texts and the feasibility of the incorporation of the two cultures in a given social and cultural context. Thus researchers can make an in-depth study of translators' thoughts, linguistic, cultural or aesthetic orientations, along with the corresponding translating strategies. It can be seen that cultural turn in translation studies has at least theoretically triggered remarkable advance of translation studies in China. Therefore, much importance has been attached to culture-specific items in the study of English translations of masterpieces. Statistical method and case study have been employed in the analysis of English versions. The study of culture factors in the English text of Wen Xin Diao Long is closely linked with the investigation of translator's strategy and restrictions in the process of translating. We can conclude that culture-bound study in the translated texts of ancient Chinese masterpieces is or will be a permanent topic for discussion.

WANG (2010) has explored the importance of choice of words, syntactical and textual arrangement and solutions to cultural differences from the perspective of culture. Drawing upon the principle of the harmonization and equality of global culture, GUO (2010) has discussed systematically the purpose, nature and principles of translation of ancient Chinese philosophy works. Such discussion is intended to retain Chinese cultural individuality and its identity while promoting the competition and incorporation of different cultures. As for the translation of ancient Chinese Philosophy, the translators should have to follow the principle of keeping its cultural individuality, minimizing the loss of cultural elements and balancing the pragmatic efficiency. 
In the past 10 years, some scholars have shifted their attention to the function and the employment of Western translation theories and literature criticism from their introduction. Deconstructionism has been universally applied to elucidate the translation process and translation result particularly in terms of the translation of ancient Chinese masterpieces. Likewise, feminism has been used to analyze the translations of ancient Chinese masterpieces (ZHANG \& CHEN, 2003). These theories, however, are so abstract or esoteric that they can be considered as powerless, empty and unconvincing.

It is worthwhile to point out that the choice of the translated texts is almost affected by researchers' personal preference. In general, the translated texts of ancient Chinese Classics such as literature works would be their first choice whereas English translations of nonliterary works have almost remained uninteresting. Similarly, some Western sinologists, in particular, British and American sinologists, preferred to translate literature works of ancient Chinese Classics, which are possessed of Oriental Flavor, and readily accepted among the target readers. As for the research of the translation of literary texts, duplicated researches have become very remarkable. There are at least 70 academic papers on the study of Quiet Night Thoughts which appear in journals. And the number of papers on Book of Songs has amazingly reached more than 150 in journals. The studies of English translations of nonliterary works have so far not been totally neglected. Based upon analysis of the translation of titles or subtitles, JIANG (2006) has discussed the points in the translation of Book of Tea such as the possible integration of form and meaning in translation and the feasibility of similarity in meaning and spirit.

Some books like A History of Translation of Ancient Chinese Classis, An Anthology of Chinese Masterpieces in English Translation, and The Reception and Translation of Ancient Chinese Novels and Dramas in the Foreign Land have supplied a large amount of information for Chinese researchers and their publications have broadened researchers' vision to a large extent. In a nutshell, we have found that there are still some problems that emerged in our research although there have been remarkable progress in the study of English translation of ancient Chinese Classics during the past 30 years. In order to solve such problems in our study, we have to make adjustments in terms of methods, perspectives and even accumulation and selection of closely related sources as well.

\section{Future Prospects}

It is definitely of necessity to provide an exact definition of Dian Ji, Ancient Chinese Classics, before we commence to present a broad vision of the study of English translations of ancient Chinese Classics. In accordance with Chinese Comprehensive Dictionary, Dian $J i$ is defined at the two levels as: the important ancient documents and books; records on codes and institutions. Such a definition has been universally acknowledged in the Chinese academic research community. To be strict, Dian Ji refers justifiably to the documents and books of predominating importance before 1911, which include books on social and natural sciences, and philosophy. In a sense, our research contains both English translations of literary works and translations of books on social and natural sciences like law, medicine, economy, agriculture, geography, etc. WANG (2009, pp. 17-22) has formulated his own understanding of the translating of ancient Chinese Classics and their exegesis that the definition of key terms can be regarded as a supplement to the translated texts, and translations which are made very pellucid should represent the function and style of the original, and that the investigation can be involved in the translators' subjectivity, the reception of the translated texts and their 
corresponding social and cultural contexts. Moreover, the researchers should shift their work to the study of artistic quality and poetic function as well. Here are some possible suggestions for the future research as follows:

\section{To Enlarge the Objects of Research}

As discussed above, the early researches concentrated largely on the English translations of Ancient Chinese Classics, in which the study of translated literary texts became predominant. Therefore, it is absolutely of necessity to promote the study of translated nonliterary texts such as Compendium of Materia Medica, ${ }^{1}$ The Yellow Emperor's Classics of Internal Medicine, Commentary on "Waterways Classics", etc. Naturally, it is very valuable to explore the translators' motivation, like the selection of the original texts, their translating strategies and their intended readers. One more point is that researchers should move their focus to the translators' contribution to the target culture and language. Take the translation of $A$ Dream of Red Mansions ${ }^{2}$ for example. There are two complete translated English texts. As for the research of its English texts, there are more than 500 academic papers in Chinese journals. Most of researches vary widely from the translation of main characters' names, the titles of chapters, the poems, to the comparative study of the two translated texts, summarization of the previous study of the two English texts, from the cultural, linguistic and aesthetic perspectives. The study of its English texts far exceeds that in Romance of the Three Kingdoms and Heroes of the Marshes in number. Similarly, the study of the English texts of Carving a Dragon at the Core of Literature has commanded its field in terms of the study of the English translations of books on Literary criticism. WANG Kuo-wei's Jen-Chien Tz'u-hua Tu, has been highly acclaimed since its publication in 1910, which compares favorably with Carving a Dragon at the Core of Literature. Jen-Chien Tz'u-hua was first translated by Tu Ching-I in 1969 and its second translation was produced in 1977 by American sinologist Adele Austin Rickett. Even the publication of its second translation has not drawn the attention of researchers. Is it not a sharp contrast?

Perhaps, such translated texts as Compendium of Materia Medica, Exposition of the Works of Nature, and A Complete Treatise on Agriculture have still not received timely attention. It is undeniably an embarrassment to grant so little effort to translated masterpieces. Possibly, researchers' lack of expertise plus the length of the translated texts has consequently led to so few research results. As for the study of the above English texts, researchers should dedicate themselves to the analysis of the social contexts, translators' attitude and poetics as well. In analyzing the translated texts, for instance, there is little point in discussing whether target language words match those in the target language in isolation from a consideration of the translator's whole worldview, particularly his translating process. Furthermore, translating process is a very interesting topic well worth discussion. Generally, the translated texts display the translator's final decisions, which is an end-product as a result of a decision-making process. By making a meticulous analysis of the translated text(s), researchers may have access to pathways leading to translators' decisions, particularly to the dilemmas to be resolved by the translators.

\footnotetext{
${ }^{1}$ Compendium of Materia Medica, a book on Chinese herbal medicine, translated by LUO Xi-wen, was published by Foreign Language Press in 2003.

2 One more English version of Hong Lou Meng, A Dream of Red Mansions, produced by LIN Yu-tang 50 years ago, is kept on file in Japan.
} 


\section{To Employ More Research Methods}

A comparative analysis is of absolute necessity to the study of translated Chinese classic texts. In addition to analysis of all the inevitable of the translated texts, importance can be attached to more systematical clarification of the translator's motivation as well as the process of translating. The tendency to neglect the process involved in the act of translating lies behind the reduplication of the investigation of the translated texts of ancient Chinese Classics in recent years. Undoubtedly, researchers can attempt to fulfill their studies from other perspectives, for instance, by employing corpus in the studies of translated classic texts. By sampling in the choice of words, researchers may find the reasons for the selection of lexical items and syntactical arrangement to serve the translators' purpose, communicative, semantic, cultural or aesthetical. Meanwhile, some efforts can be spent on the analysis of the feasibility of the complete and accurate transcript of the original so as to ensure whether the translated texts can serve corresponding aims, i.e., the translator's intention, the aesthetic expectation of the target readers, the fundamental function of the source text and the target texts as well.

As for the study of the English translation of Strange Stories From a Chinese Studio, we do not fail to analyze the translators' (Western sinologists) tolerance of Chinese mythological stories. Herbert Giles, who thought it is pure and beautiful, simple and powerful, decided to translate this masterpiece in order to present the English reader a full picture of stories overflowing with strong oriental flavor. Therefore, Giles' English translation of Strange Stories From a Chinese Studio has been highly acclaimed among the target readers as the Gem of the Oriental Literature. According to statistics, there are 17 English translations of Strange Stories From a Chinese Studio. In a sense, a corpus-based study is possible. It is necessary to make our investigation more systematical and objective by analyzing the reasons for the selection of translating strategies, including translator's annotation, prefaces or introduction, and even translator's preference in choice of words, etc. Such wide and deep investigation will help to understand the translators' ideology, cultural or aesthetic orientation as well, which entails an in-depth analysis indeed.

\section{To Analyze External Factors}

External factors refer mainly to those closely linked with the translated texts, such as translator's social context, patron, initiation and the target receptors. Social context usually presents a possibility for the reception of the translated texts. A great many ancient Chinese masterpieces were partially translated into English at its early stage. James Legge's Chinese Classics falls rightly under the category of the partial translation. We should spend some energy in exploring the reason why Legge partly translated a full Chinese literary text. For instance, it is due mostly to the fact that the intended readers at that time could tolerate and accept some texts in which they were keenly interested only. As MA and REN (1997, p. 23) have summarized that the translation of ancient Chinese Classics ranged from abridged translation to full translation, from casual translation to adequate translation; and the quality of translations had been improved substantially. When we analyze the reason that the translated Selected Tales From Liao-Chai has been unpopular among the English-speaking community, we have found that typically the translators were influenced negatively by the ideology in the early 1980s, particularly, which the hatred of the main characters of the original can be sharply felt in the translation. It is undoubtedly a pity for YANG Xian-yi's translation of Selected Tales From Liao-Chai to suffer from flat refusal among the reading public. On the contrary, having taken into consideration the target readers' aesthetic expectation and 
reading habits, Benjiamin Chia selected some of stories in the Strange Stories From a Chinese Studio and renamed them Chinese Tales of Supernatural, which has been highly received among the English readers. American Sinologist put it justifiably that the translation is very elegant and natural.

In other words, the study of external factors is essentially necessary to improve the quality of translations. In particular, the translators' social context and the receptorship should be not neglected in the study of the translated texts. Otherwise, such a study can be readily considered to be subjective and unscientific.

Another possible task for the future is a comprehensive detailed history of translated texts of Chinese Classics. It is really a rewarding undertaking although it may require the collaboration of a group of scholars specializing in different periods and genres but sharing a common concept of literary history. Its eventual usefulness is obvious. Finally, one more suggestion is the possibility of a journal in English devoted to the study of translated texts of Ancient Chinese Classics or closely bound subjects, just as International Society of Eco-translatology has run its own journal, Journal of Eco-translatology. Some professional journals concerned with translation studies are predominantly oriented towards theoretical studies, philosophically and culturally or linguistically. Very few articles on such topics appear only occasionally in some journals. A new journal, providing a forum for different views and an outlet for the works of scholars in the field, particularly for younger scholars, will seemingly meet such a genuine need. Some other work has yet to be done: the compilation of a dictionary, including glossaries, indexes, concordances, and so forth. There, after all, would be both aids to the study of translated texts of Chinese Classic Works and contributions to the study itself.

\section{Conclusion}

In essence, there are no marked differences between the study of English versions of Chinese Classic masterpieces and some other points in translation studies in theoretical foundation, research framework and methods. However, such a study is more trans-regional-and-cultural and cross-epoch. Our focus should be upon some problems arising from the cultural and historical differences between the East and West that have yet to be solved. Anyway, a positive attitude towards the Classic Works, the primary sources of our culture, particularly the English of Ancient Chinese Works, is civilized and admirable. It increases our opportunities to understand the meaningful qualities of the original and their translations, which, in turn, are much beneficial to enriching and deepening our studies. The primary goal of the study of translations of Chinese Classics rests here. Even the ever-increasing modern translation studies have facilitated the study of the English translations of ancient Chinese masterpieces substantially, the latter still compares unfavorably with other dimensions in translation studies. The improved study of the translations of ancient Chinese Classics depends heavily upon the scientific and systematic methods. Such methods, according to YAN (2000, p. 14), are principles, conventions and institutions that should be followed among the communities of scientific research and that can be applied as a yardstick for knowledge system and truth in return. The study of the English translated texts of ancient Chinese classic works should be shifted from the traditional prescriptive one to the descriptive one accordingly. Such a method can be generally helpful in describing some problems and the feasibility of norms to be followed as well as the universals in the study of translation. Only systematic and scientific methods or new perspectives will trigger a boom in the study of translated Chinese Classic Works. 


\section{References}

FAN, Y. (2006). English translation on Chinese ancient literature and philosophy. Journal of Liaoling University, 34(3), 58-60.

GUO, S. X. (2010). On the purpose, nature and principles in translating traditional Chinese philosophical Classics. Journal of An Yang Normal University, 11(1), 1-5.

JIANG, J. S., \& PENG, L. Y. (2006). Cultural context and the translation of Chinese Classics: Reflections on a research topic. Foreign Languages in China, 3(2), 72-75.

JIANG, Y., \& JIANG, X. (2006). On the meaning-form conformity in translating Chinese Classics-A case study in translating the chapter titles of The Classic of Tea. Journal of Dalian University of Technology (Social Sciences), 27(2), 80-85.

MA, Z. Y., \& REN, R. Z. (1997). A series of translation studies in China. Wuhan: Hubei Education Press.

PAN, W. G. (2004). Translating into/out of one's mother tongue: On the feasibility of translating Classics into English by native Chinese translators. Chinese Translators Journal, 25(2), 40-43.

PU, S. L. (1976). Chinese tales of supernatural. (B. Chia, Trans.). London: OUP.

PU, S. L. (1982). Selected tales from Liao-Chai. (X. Y. YANG \& G. YANG, Trans.). Beijing: Foreign Publishing House.

WANG, H. Y. (2009). An anthology of Chinese masterpieces in English translation. Beijing: Foreign Language Teaching and Research Press.

WANG, H. Y. (2010). Concepts, theories and skills of translation of Chinese Classics. Journal of Dalian University, $31(1), 127-133$.

YAN, C. S. (2000). Quantitative research methods in social sciences. Xi'An: Xi'An Jiaotong University Publishing House.

YUAN, J. X. (1987). An analysis of The Old Drunkard's Arbour Translated by A. Giles. Chinese Translator's Journal, 7(5), 44-48.

ZHANG, R. E., \& CHEN, D. Y. (2003). On the translation of the verdict poems in Hongloumeng from the angle of feminism. Shandong Foreign Languages Journal, 24(6), 91-93. 